\title{
NIH: a century of science for health
}

In 1887 a one-room Laboratory of Hygiene was established on Staten Island, New York, in response to public fears about the spread in the United States of yellow fever, cholera and tuberculosis. Direct descendant of that laboratory is the National Institutes of Health, based at Bethesda, Maryland, the largest and most successful organization ever dedicated to biomedical research. At the end of a year of centennial celebrations, which culminated last week in a gathering of alumni on the campus at Bethesda, two former Directors, Robert $Q$. Marston and Donald S. Fredrickson, reflect on the salient events in NIH's recent history and look to the future of this giant of the biomedical research world.

\section{Dilemmas of decision-making}

\section{Robert Q. Marston}

ONE hundred years ago, the Laboratory of Hygiene on Staten Island was set up as a mission-orientated unit. That mission was health, and health has continued as and remains the object of NIH's endeavours.

The modern NIH dates from the demobilization activities at the end of the Second World War, when it was given the responsibility for the administration of about 250 wartime research projects in progress at universities, medical schools and pharmaceutical companies. Thus began the powerful extramural programmes of NIH. These programmes, accounting for about 90 per cent of the NIH budget, permanently changed biomedical research through the sheer amount of money made available (almost five billion dollars), the number of institutions involved $(1,650$ of them, working on nearly 28,000 projects) and by the dependence on peer review of scientific merit as the crucial factor in the distribution of funds.

Since then, NIH has grown to include 12 separate research institutes and seven divisions or centres that support and promote research. It also includes the National Library of Medicine, the world's largest research library in a single scientific and professional field. Approximately 2,000 scientists conduct research in the laboratories at Bethesda. The activities in these laboratories and clinics, and the focus of constant meetings of study sections and councils debating the distribution of extramural funds, is on the use of science to improve health.

During the $1960 \mathrm{~s}$, great changes occurred in health care in the United States. Medicare and Medicaid were established as payment mechanisms for the aged and the poor. Through the Health Manpower Act, the federal government began direct support of education in the health fields. Because of its close affiliation with medical schools, NIH was given the responsibility, for a few years, of implementing this legislation.

This was also a period of considerable emphasis on bringing the benefits of research to patients more rapidly. Success in the space programme had led many to believe that more effort, better organiz-

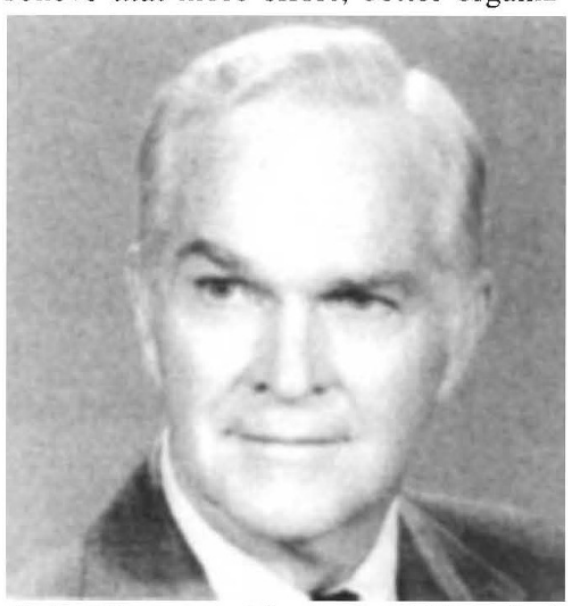

Robert Marston - "the success of biomedical research will be increasingly dependent on progress in understanding the basic nature of life".

ation and more money would accelerate the movement of research results from the laboratory bench to the patient's bedside.

Regional Medical Programs (RMPs) for heart, cancer and stroke were established in 1965 because of the belief in Congress and elsewhere that individuals and even institutions cannot cope with the complexities of modern medicine in isolation. Funds were provided to encourage and assist in the establishment of regional cooperative agreements among medical schools, research institutions and hospitals for research and study sections (including continuing education), and for related demonstrations of patient care in the fields of heart disease, cancer, stroke and associated diseases. Funds were also provided to afford to the medical pro- fession and medical institutions, through such cooperative arrangements, the opportunity of making available to their patients the latest advances in the diagnosis and treatment of these diseases. For a few years, the NIH also had the role of implementing RMPs, and I came to $\mathrm{NIH}$ as the first Director of the Programs. Despite much excitement and considerable accomplishments in several parts of the country, RMPs passed away with many of the "Great Society" initiatives.

The fact that Health Manpower and Regional Medical Programs were placed in NIH underlines the special relationship between NIH and health educational schools throughout the United States. Over half of the extramural funds go to these schools. The advisory committees, both at the study section and the council level, are well represented by their faculties. For several years, the best of the young academics were able to fulfil their military obligations by a two-year period at NIH. Strong pre- and post-doctoral training programmes sponsored by NIH in the health educational institutions produced an additional bond.

By the early 1970 s, NIH was back to the single responsibility for the conduct and support of biomedical research. Even its one regulatory component, the Bureau of Biological Standards, had been moved to the Food and Drug Administration. The drive to accelerate progress against dreaded diseases had not abated, and in 1971 the National Cancer Act became law. Among the many issues raised in this complex debate, none was more important to the scientific community than the question of targeted research versus investigator-initiated research. In short, the so-called "war on cancer" dramatized the continuing central question for all biomedical research institutions and research support institutions - how best to organize serious research, and who should make the decisions over priorities.

$\mathrm{NIH}$ has long supported a highly decentralized structure of semi-autonomous disease-orientated divisions, supplemented by several support units at the Director of NIH's level. The strong intramural programme has given administrators instant access to the substance of science; in addition, the Deputy Director for Science meets weekly with the scientific directors of the individual institutes. Hundreds of scientists convene in Bethesda as members of study sessions, councils and special advisory groups and add their expertise to the environment in which science policy is evolved. With this background, it is inevitable that science 